OPEN ACCESS

Edited by:

Gi-Ra Yi,

Sungkyunkwan University,

South Korea

Reviewed by:

Wengang Liu,

Northeastern University, China

Virendra Patil,

Korea Electronics Technology

Institute, South Korea

*Correspondence:

Jian Liu

vacation2008@126.com

Specialty section:

This article was submitted to Colloidal Materials and Interfaces,

a section of the journal

Frontiers in Materials

Received: 18 September 2019 Accepted: 30 December 2019

Published: 23 January 2020

Citation:

Zeng Y, Liu J, Dong W, Hao J and Wang Y (2020) Study on Sulfide Layer Attenuation Behavior of Smithsonite During Sulfidization Flotation.

Front. Mater. 6:347.

doi: 10.3389/fmats.2019.00347

\section{Study on Sulfide Layer Attenuation Behavior of Smithsonite During Sulfidization Flotation}

\author{
Yong Zeng ${ }^{1}$, Jian Liu ${ }^{1,2 \star}$, Wenchao Dong ${ }^{2}$, Jiamei Hao ${ }^{1}$ and Yu Wang $^{2}$ \\ ${ }^{1}$ State Key Laboratory of Complex Nonferrous Metal Resources Clean Utilization, Kunming University of Science and \\ Technology, Kunming, China, ${ }^{2}$ Faculty of Land Resource Engineering, Kunming University of Science and Technology, \\ Kunming, China
}

The S content on the surface of smithsonite plays a decisive role in smithsonite flotation. In this study, the attenuation behavior of smithsonite surface sulfide layer was investigated by inductive coupling plasma mass-spectrometric (ICP-MS) and X-ray photoelectron spectroscopic (XPS). The results of smithsonite surface $S$ adsorption capacity tests indicated that smithsonite surface sulfide layer is not stable, and the $\mathrm{S}$ adsorption capacity decreased from $22.12 \times 10^{-7}$ to $20.52 \times 10^{-7} \mathrm{~mol} / \mathrm{g}$ from 6 to $8 \mathrm{~min}$ with a decrease of $7.2 \%$. $\mathrm{NH}_{4} \mathrm{Cl}$ can enhance the stability of $\mathrm{S}$ adsorption on the smithsonite surface. After adding $\mathrm{NH}_{4} \mathrm{Cl}$, the $\mathrm{S}$ adsorption capacity on smithsonite surface for sulfidization 8 min was increased by $10.9 \%$. However, the S falling off capacity tests showed that the S-species will fall off from smithsonite surface under mechanical stirring. The largest amount of falling off capacity is $3.701 \times 10^{-7} \mathrm{~mol} / \mathrm{g}$, with a decreased percentage of $16.7 \%$. XPS analysis indicated that monosulfide, disulfide, polysulph, sulphite, and sulfate are all the sources of the S-species falling off from the surface, and the relative content of disulfide on smithsonite surface has the greatest decreasing, reaching $0.33 \%$. Mechanical stirring is an important reason for sulfide layer attenuation of smithsonite surface. Monosulfide, disulfide, and polysulph on smithsonite surface can be converted into soluble sulphite and soluble sulfate, resulting in the decrease of S content on smithsonite surface.

Keywords: attenuation, smithsonite, sulfide layer, mechanical stirring, sulfidization

\section{INTRODUCTION}

Zinc sulfide ore is the main source of zinc metal, and sphalerite is a representative mineral of it. Compared with zinc oxidized ores, the processing method and reagent system of zinc sulfide ores are simpler (Hosseini and Forssberg, 2006, 2007; Ejtemaei et al., 2014; Chen et al., 2018). Although zinc sulfide ores have more advantages in mineral processing, it is undeniable that with the decreasing of zinc sulfide ores in nature, zinc oxide ores will be more widely exploited (Wu et al., 2017). Smithsonite, chemical formula is $\mathrm{ZnCO}_{3}$, is one of the three basic zinc oxide ore varieties with economic value (Ejtemaei et al., 2014). In mineral processing, flotation is the most common and useful method to separate it from gangue minerals (Rao and Finch, 2003; Bulatovic, 2007; Kashani and Rashchi, 2008; Ejtemaei et al., 2014). It is generally known that the hydrophobicity of minerals surface and adsorption capacity of collector on minerals surface are the decisive factors in mineral flotation (Xing et al., 2017; Irannajad et al., 2019). However, for smithsonite, the weak surface hydrophobicity and the poor response of surface to the collector are the major difficulties 
in its flotation (Liu et al., 2018a,b; Chen et al., 2019). In order to improve the hydrophobicity of smithsonite surface, potassium sulfosalt, amine salts, ammonium salts, xanthate and $\mathrm{Cu}$ sulfate are widely used in flotation as flotation reagents (Hosseini and Forssberg, 2006; Chen et al., 2019). The flotation methods of smithsonite with these reagents can be classified into sulfidization-amine flotation and sulfidization-xanthate flotation (Wu et al., 2015; Kai et al., 2018; Chen et al., 2019). The sulfidization amine flotation is a process which needs a necessary pretreatment of desliming to improve the sulfidization efficiency due to the high sensitivity of amine to slime. However, the pretreatment process would lead to the significant loss of zinc in flotation process (Kiersznicki et al., 1981; Ejtemaei et al., 2011; Chen et al., 2019). In addition, the amine salts are very sensitive to the $\mathrm{pH}$ of the pulp, and have low activity under alkaline condition (Ejtemaei et al., 2014). Therefore, sulfidization-xanthate flotation is also effectively applied to concentrate smithsonite in many concentrators which are not suitable for sulfidization-amine flotation (Hosseini and Forssberg, 2006; Chen et al., 2019).

For sulfidization-xanthate flotation of smithsonite, sulfidization is the most critical process. As a cheap chemical, $\mathrm{Na}_{2} \mathrm{~S}$ is the most widely used sulfidization agent in flotation of smithsonite. During flotation process, the dissociation of $\mathrm{Na}_{2} \mathrm{~S}$ and the further hydrolysis of $\mathrm{S}^{2-}$ would produce a large amount of $\mathrm{S}^{2-}$ and $\mathrm{HS}^{-}$(Ejtemaei et al., 2014). HS ${ }^{-}$is the dominant species in alkaline pulp solutions. Because of the adsorption of $\mathrm{HS}^{-}$on smithsonite surface, the $\mathrm{ZnCO}_{3}$ on smithsonite surface will be converted into $\mathrm{ZnS}$ according to the reaction (1) and reaction (2) (Ejtemaei et al., 2014; Feng and Wen, 2017).

$$
\mathrm{ZnCO}_{3}+\mathrm{HS}^{-} \rightleftharpoons \mathrm{ZnS}+\mathrm{HCO}_{3}^{-}
$$

Since smithsonite is a soluble carbonate, the $\mathrm{Zn}(\mathrm{OH})_{2}$ precipitation can occur at alkaline $\mathrm{pH}$.

$$
\mathrm{Zn}(\mathrm{OH})_{2}+\mathrm{HS}^{-} \rightleftharpoons \mathrm{ZnS}+\mathrm{H}_{2} \mathrm{O}+\mathrm{OH}^{-}
$$

Sphalerite $(\mathrm{ZnS})$ is a typical sulfide ore. Most of sulfide ores have good floatability, but the sphalerite is an exception (Chandra and Gerson, 2009; Liu et al., 2018). The properties of ZnS formed on smithsonite surface are similar to the sphalerite, i.e., the poor hydrophobicity and hard adsorption of collectors. In order to improve the hydrophobicity of smithsonite surface after sulfidization, ammonium salts, $\mathrm{CuSO}_{4}$, and long-chainalkyl xanthate are respectively usually added as strengthening sulfiding agent, activator and collector in froth flotation. After the adsorption of $\mathrm{NH}_{4}^{+}$and $\mathrm{Cu}^{2+}$ on sulfidization-smithsonite surface, the $\left[\mathrm{Zn}\left(\mathrm{NH}_{3}\right)_{\mathrm{n}}{ }^{2+}\right](n=1-4)$ complex and $\mathrm{CuS}$ would be formed on the surface. Unlike $\mathrm{ZnS},\left[\mathrm{Zn}\left(\mathrm{NH}_{3}\right)_{\mathrm{n}}{ }^{2+}\right](n=1-4)$ and $\mathrm{CuS}$ have a strong interaction with xanthate (Popov and Vučini, 1990; Liu et al., 2014).

The sulfidization of smithsonite surface plays a key role on its subsequent interaction with the activator and collector, and the interaction further effect the flotation performance. The thickness and its area of surface sulfide layer are the key to the sulfuration performance of smithsonite. Much researches have been done on surface sulfidization of smithsonite in
TABLE 1 | Chemical composition of pure smithsonite samples.

\begin{tabular}{lccccccc}
\hline Element & $\mathbf{Z n}$ & $\mathbf{F e}$ & $\mathbf{C a O}$ & $\mathbf{A l}_{2} \mathbf{O}_{3}$ & $\mathbf{P b}$ & $\mathbf{C d}$ & $\mathbf{S i O}_{2}$ \\
\hline Content (\%) & 50.50 & 0.4 & 0.55 & 0.50 & 0.67 & 0.46 & 1.74
\end{tabular}

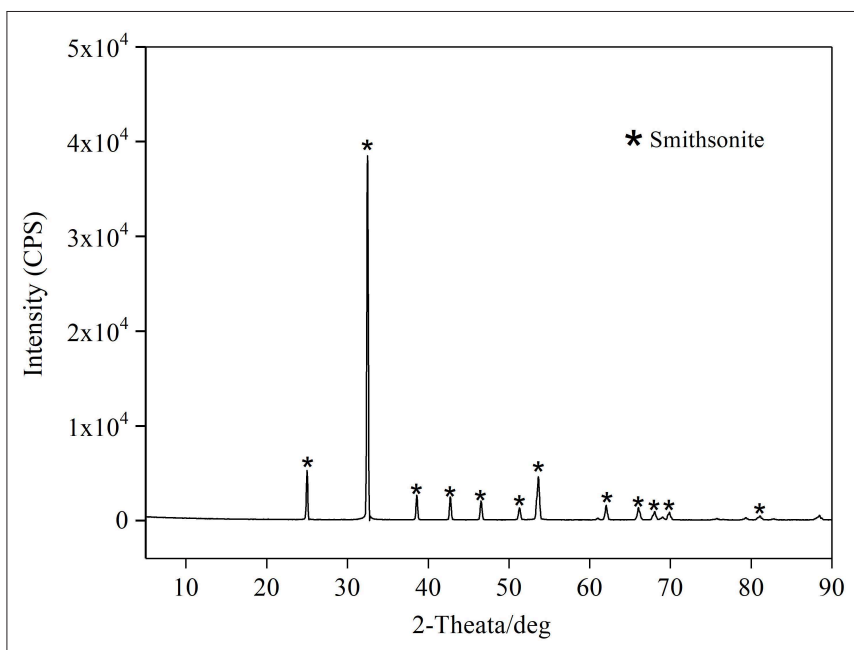

FIGURE 1 | X-ray diffraction pattern of the pure smithsonite samples.

previous, and some studies have shown that the flotation smithsonite is not proportional to sulfurization time (Kashani and Rashchi, 2008). However, there are few investigations about the attenuation law and attenuation characterization of surface sulfide layer with time. In present study, the attenuation law and attenuation characterization of surface sulfide layer with time during sulfidization, and its effects on flotation are investigated through inductive coupling plasma mass-spectrometric (ICP-MS) and X-ray photoelectron spectroscopic (XPS).

\section{MATERIALS AND METHODS}

\section{Materials and Reagents}

The smithsonite is purchased from Kunming, Yunnan Province. After be crushed simply, the smithsonite sample grinds with agate torsion mortar in the dry environment. The fraction size of -74 $+38 \mu \mathrm{m}$ grinding product was separated by using standard sieve and used for subsequent experiments. As shown in Table 1, the chemical composition analyses showed that the sample contained $50.50 \% \mathrm{Zn}$, with a high purity of $97 \%$. The X-ray diffraction pattern of the sample is shown in Figure 1.

Analytical-grade $\mathrm{Na}_{2} \mathrm{~S}$ and $\mathrm{CuSO}_{4} \cdot 5 \mathrm{H}_{2} \mathrm{O}$, commercial-grade potassium butyl xanthate were used as sulfidizing agent, activator and collector, respectively. Sodium hydroxide $(\mathrm{NaOH})$ and hydrochloric acid ( $\mathrm{HCl}$ ) with more than $98 \%$ purity were used as $\mathrm{pH}$ regulators. Pure deionized water with a resistivity of $18 \mathrm{M} \Omega$ obtained from a Milli-Q5O system (Billerica, MA, USA) was used in all the experiments. 


\section{Smithsonite Surface S Adsorption Capacity Tests}

$S$ adsorption capacity tests were carried out using ICP-MS. The freshly prepared $\mathrm{Na}_{2} \mathrm{~S}$ solution with concentration $1 \times$ $10^{-4} \mathrm{~mol} / \mathrm{L}$ was used for sulfidization in the beaker. One gram smithsonite sample of ultrasonic treatment for 5 min was mixed with $40 \mathrm{ml} \mathrm{Na} 2 \mathrm{~S}$ solution. After a period of interaction, the corresponding filtrates were obtained by filtration. After that, these filtrates were used to detect the residual $S$ content in the solution by ICP-MS. The S adsorption capacity of smithsonite is calculated by the following Equation:

$$
\Gamma_{\mathrm{S}}=\frac{\left(C_{\mathrm{S}}^{\text {initial }}-C_{\mathrm{S}}^{\text {residual }}\right) \times V}{m}
$$

where $C_{S}^{\text {initial }}$ and $C_{S}^{\text {residual }}$ refer to the initial S concentration and residual $S$ concentration in solution, respectively. $\Gamma_{\mathrm{S}}$ represents the $\mathrm{S}$ adsorption capacity of smithsonite. $\mathrm{V}$ is the volume of solution; $\mathrm{m}$ is the quality of smithsonite.

For the sulfidation strengthen studies of adding $\mathrm{NH}_{4} \mathrm{Cl}$, smithsonite sample $(1 \mathrm{~g})$ was introduced into the solution $(40 \mathrm{~mL})$ which has $\mathrm{Na}_{2} \mathrm{~S}$ concentration of $1 \times 10^{-4} \mathrm{~mol} / \mathrm{L}$ and $\mathrm{NH}_{4} \mathrm{Cl}$ concentration of $3 \times 10^{-4} \mathrm{~mol} / \mathrm{L}$ (Wu et al., 2017). After that, the corresponding filtrate was obtained by filtration to detect the $S$ content.

\section{Smithsonite Surface S Falling Off Tests}

The tests of smithsonite surface $S$ falling off capacity at different mechanical stirring time were carried out by ICP-MS. The optimum sulfidization time for the maximum $\mathrm{S}$ adsorption capacity was determined at $6 \mathrm{~min}$, which is based on the tests of smithsonite surface $\mathrm{S}$ adsorption capacity. Under the same experimental conditions, multigroup filtrate residues of the sulfidization for $6 \mathrm{~min}$ was obtained by filtration and these residues were used as samples for the smithsonite surface $S$ falling off experiments. After that, these samples were added to $40 \mathrm{ml}$ deionized water for mechanical stirring with different time, and subsequently filtrated. The filtrates were used to detect the $\mathrm{S}$ content using ICP-MS.

\section{XPS Analysis}

$\mathrm{Na}_{2} \mathrm{~S}$ solution with a concentration of $1 \times 10^{-4} \mathrm{~mol} / \mathrm{L}$ was configured to deal with the smithsonite $(\mathrm{pH}=10)$. One gram smithsonite samples after ultrasonic treatment for 5 min were mixed with $40 \mathrm{ml} \mathrm{Na} \mathrm{N}_{2} \mathrm{~S}$ solution. After interaction with a specified time under mechanical stirring, the smithsonite is extracted through filtration. Subsequently, the smithsonite samples were dried in a vacuum drying.

The sulfidization products after drying was examined by using a K-Alpha+ (Thermo Fisher Scientific, Waltham, MA, USA) $\mathrm{X}$-ray photoelectron spectrometer with a monochromatized $\mathrm{Al}-\mathrm{K} \alpha \mathrm{X}$-ray source $(1,486.6 \mathrm{eV}, 6 \mathrm{~mA} \times 12 \mathrm{KV})$. Survey scans were conducted at a pass energy of $100 \mathrm{eV}$ to detect elemental compositions, and multiplex high-resolution scans were recorded at $30 \mathrm{eV}$ to obtain the XPS spectrum of each specific element. The analysis chamber's vacuum pressure was $5 \times 10^{-9}$ mbar. Subsequently, the Thermo Avantage v5.976

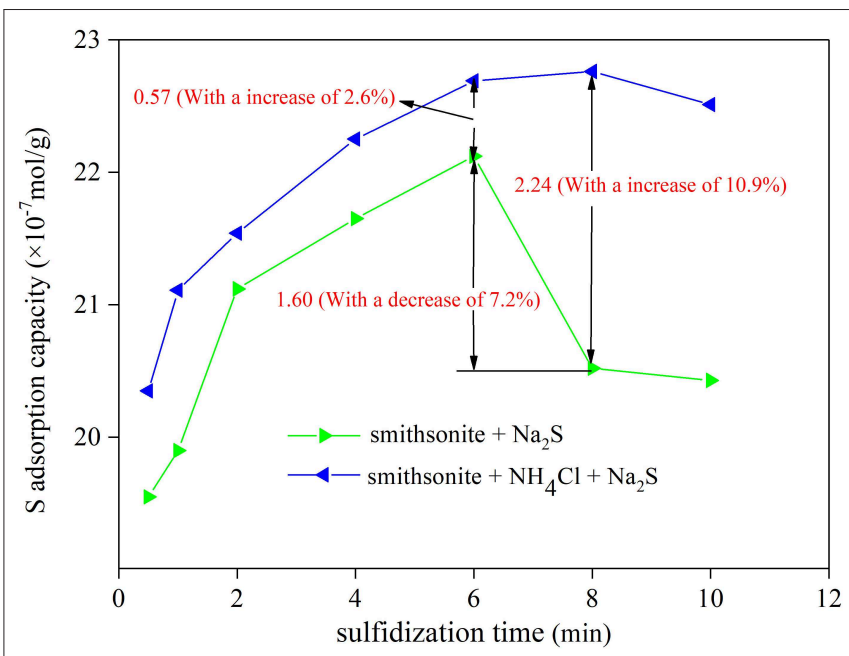

FIGURE 2 | S adsorption capacity of smithsonite surface with sulfidization time.

software was used to calculate and analyze the spectra and surface atomic ratios of the measured samples. The carbon $1 \mathrm{~s}$ spectral peak at $284.8 \mathrm{eV}$ was obtained to calibrate all of the measured spectra as an internal standard for charge compensation (Feng et al., 2017).

\section{RESULTS AND DISCUSSION}

\section{Smithsonite Surface S Adsorption Capacity Tests}

Figure 2 (green curve) shows the adsorption capacity of $S$ on smithsonite surface as function of sulfidization time. There is a peak of the adsorption capacity, which increases between 0.5 and $6 \mathrm{~min}$ and decreases between 6 and $10 \mathrm{~min}$. The maximum adsorption capacity of $22.12 \times 10^{-7} \mathrm{~mol} / \mathrm{g}$ occurs at $6 \mathrm{~min}$ of sulfidation time, however, while the sulfurization time reached $8 \mathrm{~min}$, the $\mathrm{S}$ adsorption capacity decreased sharply to $20.52 \times$ $10^{-7} \mathrm{~mol} / \mathrm{g}$, with a decrease percentage of $7.2 \%$. Obviously, the $\mathrm{S}$ adsorption capacity after $8 \mathrm{~min}$ was against the adsorption principle. The most likely cause of the adsorption capacity decrease with the sulfidation time is the $S$ falling off from smithsonite surface. It can be inferred that the $S$ adsorption on the smithsonite surface is not stable, at least in part. Kashani and Rashchi (2008) studied the effect of $\mathrm{Na}_{2} \mathrm{~S}$ conditioning time on $\mathrm{Zn}$ grade. In order to see the effect of conditioning time, 3,400 g/t Na $2 \mathrm{~S}, 356 \mathrm{~g} / \mathrm{t}$ amine, and $60 \mathrm{~g} / \mathrm{t}$ pine oil were used as flotation reagents. According to the flotation results, there is a peak of $\mathrm{Zn}$ grade, which increases between 2 and $5 \mathrm{~min}$ and decreases between 5 and $10 \mathrm{~min}$. Five minutes was considered as the optimum conditioning time. Obviously, Kashani's flotation results are in good agreement with the $\mathrm{S}$ adsorption capacity tests of smithsonite surface in Figure 2.

In addition, the relationship between smithsonite surface $S$ adsorption capacity with sulfidization time under addition $\mathrm{NH}_{4} \mathrm{Cl}$ was studied, with the results shown in Figure 2 
(blue curve). It is noticeable that the $\mathrm{S}$ adsorption capacity increased significantly compared with the absence of $\mathrm{NH}_{4} \mathrm{Cl}$. There is no $\mathrm{S}$ attenuation for sulfidization time from 2 to $6 \mathrm{~min}$, and corresponding $\mathrm{S}$ adsorption capacity only increased by 0.57 $\times 10^{-7} \mathrm{~mol} / \mathrm{g}$ (with an increase percentage of $2.6 \%$ ) after adding $\mathrm{NH}_{4} \mathrm{Cl}$. Further, $\mathrm{S}$ adsorption capacity for sulfidization $8 \mathrm{~min}$ increased by $2.24 \times 10^{-7} \mathrm{~mol} / \mathrm{g}$ (with an increase percentage of $10.9 \%$ ) after adding $\mathrm{NH}_{4} \mathrm{Cl}$ compared with the absence of $\mathrm{NH}_{4} \mathrm{Cl}$. In Figure 2, compared with the green curve, the blue curve shows that the addition of $\mathrm{NH}_{4} \mathrm{Cl}$ leads to the increase of $\mathrm{S}$ adsorption capacity on smithsonite surface. More importantly, it shows that the addition of $\mathrm{NH}_{4} \mathrm{Cl}$ can reduce the attenuation of sulfide layer on smithsonite significantly. Previous studies have suggested that $\mathrm{NH}_{4} \mathrm{Cl}$ enhances or increases the adsorption of $\mathrm{S}$ on smithsonite surfaces in sulfidization (Wu et al., 2017; Feng et al., 2019). However, the smithsonite surface $S$ adsorption capacity tests shows that aside from the $\mathrm{NH}_{4} \mathrm{Cl}$ enhancing the surface $\mathrm{S}$ adsorption, the $\mathrm{NH}_{4} \mathrm{Cl}$ will prevent the falling off of $\mathrm{S}$ adsorbed on the surface of smithsonite.

\section{Smithsonite Surface S Falling Off Capacity Tests}

To investigate the reason of S falling off from smithsonite surface, the mechanical stirring was introduced into the experiment. As shown in Figure 3, the lowest $S$ falling off capacity is $0.914 \times$ $10^{-7} \mathrm{~mol} / \mathrm{g}$ in mechanically stirring for $1 \mathrm{~min}$, with a decrease percentage of $4.1 \%$. The largest $S$ falling off capacity is 3.701 $\times 10^{-7} \mathrm{~mol} / \mathrm{g}$ in mechanically stirring for $10 \mathrm{~min}$, with a decrease percentage of $16.7 \%$. The overall trend of S falling off capacity from the sulfidization-smithsonite surface is increased with mechanical stirring time. Obviously, the mechanical stirring has a great influence on smithsonite surface $S$ content. When mechanically stirring for $3 \mathrm{~min}$, the falling off capacity of $\mathrm{S}$ reached $2.67 \times 10^{-7} \mathrm{~mol} / \mathrm{g}$, which increased by $1.756 \times 10^{-7}$ $\mathrm{mol} / \mathrm{g}$ compared with that mechanically stirring for $1 \mathrm{~min}$. The results showed that $S$ content decreases rapidly within mechanically stirring for $3 \mathrm{~min}$. However, the rate of $\mathrm{S}$ falling off decreased significantly between 3 and $10 \mathrm{~min}$, and the $S$ falling off capacity is $1.03 \times 10^{-7} \mathrm{~mol} / \mathrm{g}$ between 3 and $10 \mathrm{~min}$. It suggests that the surface sulfide layer changed significantly after stirring for $3 \mathrm{~min}$. The $\mathrm{S}$ falling off capacity will not increase with the mechanical stirring time after the stirring time exceeds $10 \mathrm{~min}$. It was concluded that the smithsonite surface sulfide layer is more stably compared with before stirring for $10 \mathrm{~min}$. In short, the mechanical stirring is an important reason of the S-species falling off from smithsonite surface.

\section{XPS Analysis}

XPS analysis can provide valuable chemical information, such as chemical compositions, elemental chemical states and elemental relative contents, on mineral surface (Liu et al., 2020). In order to investigate the changes of $\mathrm{S}$ elemental chemical states and $\mathrm{S}$-species content on smithsonite surface with the mechanical stirring time. The XPS was employed to examine the adsorption of $\mathrm{Na}_{2} \mathrm{~S}$ on smithsonite surface at different mechanical stirring time. The atomic concentrations of smithsonite samples of sulfidization for $4 \mathrm{~min}$ and $8 \mathrm{~min}$ are shown in Table 2.

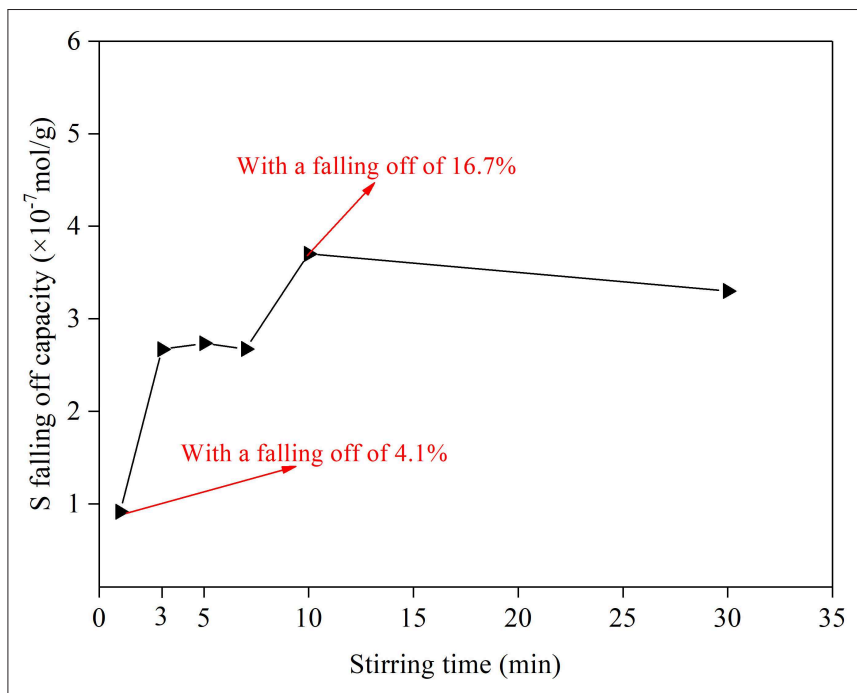

FIGURE 3 | S falling off capacity of smithsonite surface with stirring time.

TABLE 2 | The atomic concentrations of smithsonite samples at different sulfurization time.

\begin{tabular}{lccc}
\hline Sample & & Binding energy (eV) & Relative content (\%) \\
\hline Smithsonite & Zn 2p & 1021.19 & 14.97 \\
& C 1s & 289.88 & 35.57 \\
& O 1s & 531.63 & 49.46 \\
& S 2p & - & - \\
Smithsonite +S (4 min) & Zn 2p & 1022.03 & 11.09 \\
& C 1s & 289.92 & 45.33 \\
& O 1s & 532.06 & 40.10 \\
& S 2p & 162.43 & 3.49 \\
Smithsonite + S (8 min) & Zn 2p & 1021.98 & 10.71 \\
& C 1s & 290.03 & 46.32 \\
& O 1s & 532.03 & 40.22 \\
& S 2p & 162.09 & 2.75 \\
\hline
\end{tabular}

Obviously, the $\mathrm{S}$ atomic concentrations decreased from 3.49 to $2.75 \%$ from 4 to $8 \mathrm{~min}$. The results are consistent with ICP regularity.

The S2p XPS spectra of smithsonite samples sulfidization for $4 \mathrm{~min}$ and sulfidization for $8 \mathrm{~min}$ are shown in Figure 4. The S2p spectrum was usually separated to S2p3/2 and S2p1/2 spinorbit with $1.18 \mathrm{eV}$ energy separation and 2:1 intensity ratio (Acres et al., 2010; Smart et al., 2015). The S2p spectrum of sulfidization for $4 \mathrm{~min}$ is composed of five doublets $\mathrm{S} 2 \mathrm{p} 3 / 2$ peaks at $161.2 \mathrm{eV}$ from $\mathrm{S}^{2-}, 161.85 \mathrm{eV}^{2}$ from $\mathrm{S}_{2}{ }^{2-}, 163.83$ from $\mathrm{S}_{\mathrm{n}}{ }^{2-}, 166.4 \mathrm{eV}$ from $\mathrm{SO}_{3}{ }^{2-}$ and 168.6 from $\mathrm{SO}_{4}{ }^{2-}$, respectively. The S2p spectrum of sulfidization for $8 \mathrm{~min}$ is composed of five doublets S $2 \mathrm{p} 3 / 2$ peaks at $161.2 \mathrm{eV}$ from $\mathrm{S}^{2-}, 161.85 \mathrm{eV}$ from $\mathrm{S}_{2}{ }^{2-}, 163.71 \mathrm{eV}$ from $\mathrm{S}_{\mathrm{n}}{ }^{2-}, 166.4 \mathrm{eV}$ from $\mathrm{SO}_{3}{ }^{2-}$ and $168.14 \mathrm{eV}$ from $\mathrm{SO}_{4}{ }^{2-}$, respectively. (Khmeleva et al., 2005, 2010; Smart et al., 2015; Hirajima et al., 2017; Suyantara et al., 2018). Table 3 shows the S-species concentrations of the smithsonite samples sulfidization 
for 4 and $8 \mathrm{~min}$. The S-species concentrations of sulfidization for $8 \mathrm{~min}$ are significantly lower than that of sulfidization for $4 \mathrm{~min}$. The relative content decrement of various S-species in smithsonite samples sulfurized for 4-8 $\mathrm{min}$ is shown in Figure 5. Apparently, all the $\mathrm{S}$-species are the sources of the falling off S. Disulfide $\left(\mathrm{S}_{2}{ }^{2-}\right)$ has largest decrement, reaching $0.33 \%$. Sulphite and sulfate as soluble salts are most likely to exist

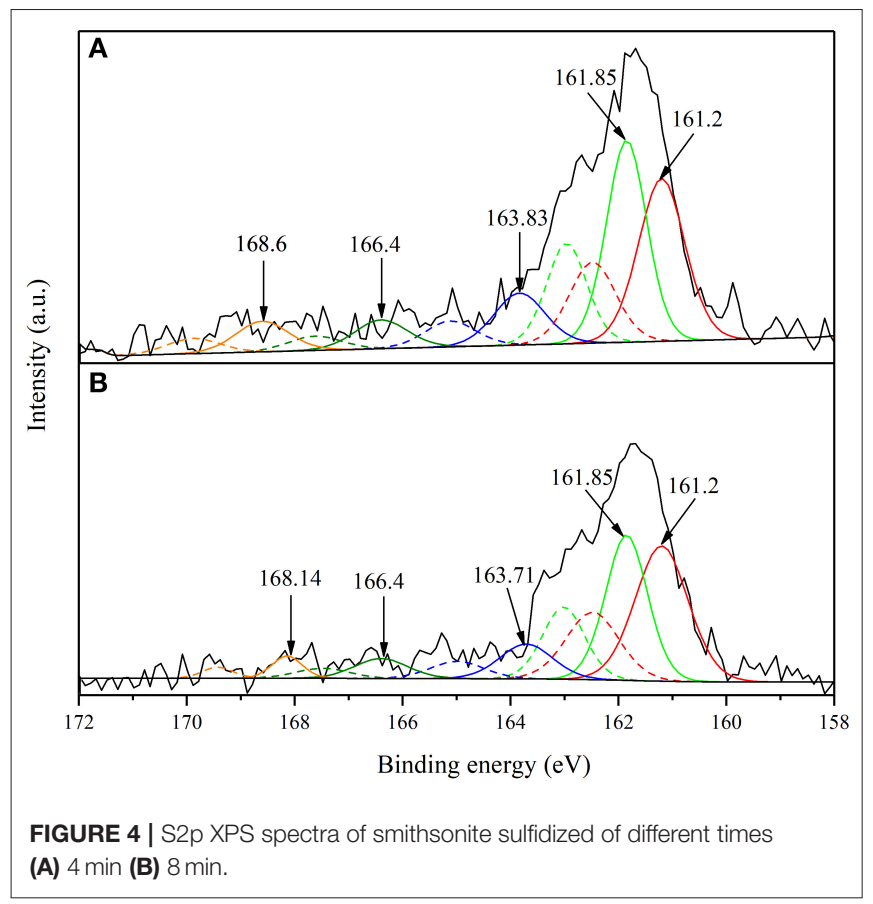

on the smithsonite surface by physical adsorption (electrostatic force adsorption). As a kind of unstable adsorption relationship, sulphite and sulfate are easy to falling off from smithsonite surface under the mechanical stirring. In addition, the presence of sulphite and sulfate indicated that surface S-species was oxidized. Monosulfide, disulfide, and polysulph can be converted into soluble sulphite and soluble sulfate, and resulting in the decreasing of smithsonite surface $\mathrm{S}$ content. Zinc monosulfide, zinc disulfide, and zinc polysulfide are the target products of sulfidation, which formed by the interaction of monosulfide, disulfide, and polysulph with $\mathrm{Zn}^{2+}$ on the smithsonite surface. Although zinc monosulfide, zinc disulfide, and zinc polysulfide have the similar surface chemical properties as sphalerite, they are not firmly exist on the smithsonite surface as a newly generated products. As a result, they are likely to falling off from smithsonite surface under mechanical stirring. Apparently, the hydrophilicity of smithsonite surface increases with the decreasing of hydrophobic sulfides (zinc monosulfide, zinc disulfide, and zinc polysulfide). However, due to the sulphite and sulfate are hydrophilic species which are similar to the surface of the smithsonite. Thus, the content of sulphite and sulfate does not significantly affect the hydrophilicity of smithsonite surface.

\section{CONCLUSIONS}

In this study, the attenuation behavior of smithsonite surface sulfide layer was studied. The smithsonite surface sulfide layer is not as stable as expected. The smithsonite surface $S$ content will not increase all the time with the increase of sulfurization time. On the contrary, the S-species of smithsonite surface will decrease when the sulfurization time exceed $6 \mathrm{~min}$, and the $S$ adsorption capacity had a decrease of $7.2 \%$ between 6 and

TABLE 3 | The S-species concentrations of smithsonite samples in different sulfurization time.

\begin{tabular}{|c|c|c|c|c|c|c|}
\hline Sample & S-species & $\begin{array}{c}\text { Binding } \\
\text { energy }(e V)\end{array}$ & FWHM/eV & $\begin{array}{c}\text { Deconvulated } \\
\text { peak area (CPS.ev) }\end{array}$ & $\begin{array}{l}\text { Relative content in } \\
\text { S-species (\%) }\end{array}$ & $\begin{array}{l}\text { Relative content in } \\
\text { smithsonite samples } \\
(\%)\end{array}$ \\
\hline \multirow[t]{5}{*}{ Smithsonite +S (4 min) } & $\begin{array}{l}\text { Monosulfide. } \\
\left(\mathrm{S}^{2-}\right)\end{array}$ & 161.20 & 1.01 & $2,148.73$ & 35.21 & 1.23 \\
\hline & $\begin{array}{l}\text { Disulfide. } \\
\left(\mathrm{S}_{2}{ }^{2-}\right)\end{array}$ & 161.85 & 0.87 & $2,303.69$ & 37.73 & 1.32 \\
\hline & $\begin{array}{l}\text { Polysulph. } \\
\left(\mathrm{S}_{\mathrm{n}}^{2-}\right)\end{array}$ & 163.83 & 1.11 & 752.92 & 12.36 & 0.43 \\
\hline & $\begin{array}{l}\text { Sulphite. } \\
\left(\mathrm{SO}_{3}{ }^{2-}\right)\end{array}$ & 166.40 & 1.15 & 433.45 & 7.12 & 0.25 \\
\hline & $\begin{array}{l}\text { Sulfate. } \\
\left(\mathrm{SO}_{4}{ }^{2-}\right)\end{array}$ & 168.60 & 1.15 & 460.45 & 7.57 & 0.26 \\
\hline \multirow[t]{5}{*}{ Smithsonite +S (8 min) } & $\begin{array}{l}\text { Monosulfide. } \\
\left(\mathrm{S}^{2-}\right)\end{array}$ & 161.20 & 1.15 & $2,040.89$ & 42.6 & 1.17 \\
\hline & $\begin{array}{l}\text { Disulfide. } \\
\left(\mathrm{S}_{2}{ }^{2-}\right)\end{array}$ & 161.85 & 0.91 & $1,731.25$ & 36.15 & 0.99 \\
\hline & $\begin{array}{l}\text { Polysulph. } \\
\left(S_{n}^{2-}\right)\end{array}$ & 163.71 & 1.15 & 524.16 & 10.96 & 0.30 \\
\hline & $\begin{array}{l}\text { Sulphite. } \\
\left(\mathrm{SO}_{3}^{2-}\right)\end{array}$ & 166.4 & 1.15 & 300.76 & 6.30 & 0.17 \\
\hline & $\begin{array}{l}\text { Sulfate. } \\
\left(\mathrm{SO}_{4}{ }^{2-}\right)\end{array}$ & 168.14 & 0.65 & 191.18 & 4.01 & 0.11 \\
\hline
\end{tabular}




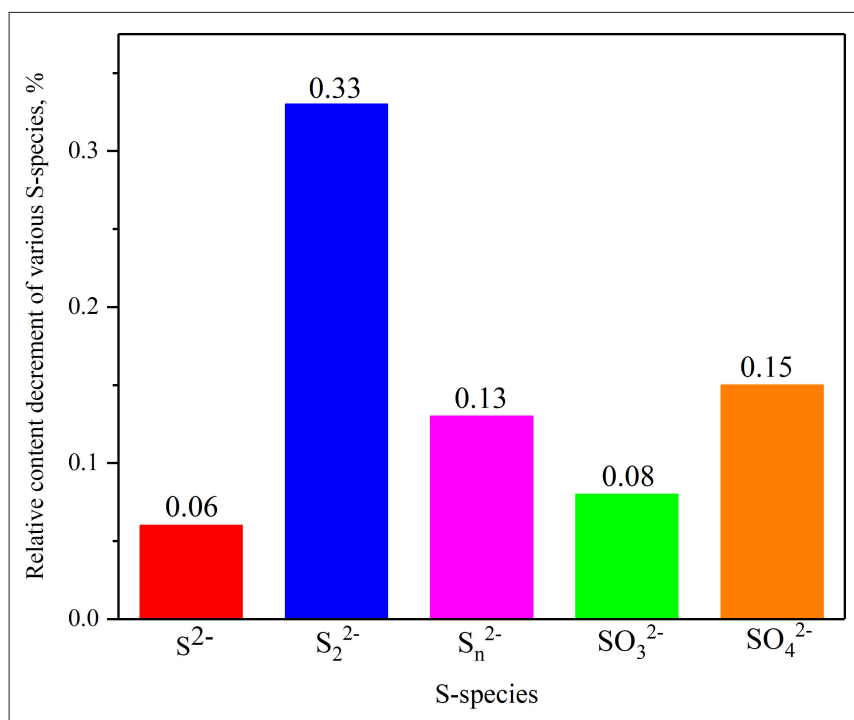

FIGURE 5 | Relative content decrement of various S-species in smithsonite samples from sulfidization for 4-8 min.

$8 \mathrm{~min}$. $\mathrm{NH}_{4} \mathrm{Cl}$ enhances the stability of $\mathrm{S}$ adsorption on the smithsonite surface, reduces the $S$ falling off from smithsonite surface and improves its hydrophobicity. It is one of the reasons why $\mathrm{NH}_{4} \mathrm{Cl}$ can enhance sulfidization. Mechanical stirring has a great influence on $S$ content of smithsonite surface. It is an important cause of S-species falling off. The largest $S$ falling off capacity is $3.701 \times 10^{-7} \mathrm{~mol} / \mathrm{g}$, which appeared in mechanically stirring for $10 \mathrm{~min}$ with a decrease of $16.7 \%$. The XPS analysis

\section{REFERENCES}

Acres, R. G., Harmer, S. L., and Beattie, D. A. (2010). Synchrotron PEEM and ToFSIMS study of oxidized heterogeneous pentlandite, pyrrhotite and chalcopyrite. J. Synchrotron Radiat. 17, 606-615. doi: 10.1107/S0909049510026749

Bulatovic, S. M. (ed.). (2007). "Flotation of sulfide ores," in Handbook of Flotation Reagents: Chemistry, Theory and Practice (Amsterdam: Elsevier Science \& Technology Books), 87-92.

Chandra, A. P., and Gerson, A. R. (2009). A review of the fundamental studies of the copper activation mechanisms for selective flotation of the sulfide minerals, sphalerite and pyrite. Adv. Colloid Interface Sci. 145, 97-110. doi: 10.1016/j.cis.2008.09.001

Chen, Y., Liu, M., Chen, J., Li, Y., Zhao, C., and Mu, X. (2018). A density functional based tight binding $(\mathrm{DFTB}+)$ study on the sulfidizationamine flotation mechanism of smithsonite. Appl. Surf. Sci. 458, 454-463. doi: 10.1016/j.apsusc.2018.07.014

Chen, Y., Zhang, G., Wang, M., Shi, Q., Liu, D., and Li, Q. (2019). Utilization of sodium carbonate to eliminate the adverse effect of $\mathrm{Ca}^{2+}$ on smithsonite sulphidisation flotation. Miner. Eng. 132, 121-125. doi: 10.1016/j.mineng.2018.12.003

Ejtemaei, M., Gharabaghi, M., and Irannajad, M. (2014). A review of zinc oxide mineral beneficiation using flotation method. Adv. Colloid Interface Sci. 206, 68-78. doi: 10.1016/j.cis.2013.02.003

Ejtemaei, M., Irannajad, M., and Gharabaghi, M. (2011). Influence of important factors on flotation of zinc oxide mineral using cationic, anionic and mixed (cationic/anionic) collectors. Miner. Eng. 24, 1402-1408. doi: 10.1016/j.mineng.2011.05.018 results indicated that monosulfide, disulfide, polysulph, sulphite and sulfate are the sources of the falling off S. They are not firmly existed on smithsonite surface as newly generated products, and are easy falling off under mechanical stirring. Disulfide $\left(\mathrm{S}_{2}{ }^{2-}\right)$ has the largest decrement, with a relative content decrement of $0.33 \%$. In addition, it was inferred from the XPS analysis results that there is a transformation process from monosulfide, disulfide and polysulph to soluble sulphite, and soluble sulfate. The soluble products further results in the decrement of $S$ content on smithsonite surface.

\section{DATA AVAILABILITY STATEMENT}

The datasets generated for this study are available on request to the corresponding author.

\section{AUTHOR CONTRIBUTIONS}

JL conceived the project and designed the experiments. $\mathrm{YW}, \mathrm{YZ}, \mathrm{JH}$, and WD performed the sample preparation, characterization, and XPS analysis. YZ and JH wrote the paper. All authors discussed the results and commented on the manuscript.

\section{FUNDING}

We acknowledge the financial support from the National Natural Science Foundation of China (Grant No. 51764035), the China Scholarship Council (Grant No. 201708535015), and the Scholar Development Project of Yunnan Province (Grant No. KKSY201556033).

Feng, Q., and Wen, S. (2017). Formation of zinc sulfide species on smithsonite surfaces and its response to flotation performance. J. Alloys Compd. 709, 602-608. doi: 10.1016/j.jallcom.2017.03.195

Feng, Q., Wen, S., Bai, X., Chang, W., Cui, C., and Zhao, W. (2019). Surface modification of smithsonite with ammonia to enhance the formation of sulfidization products and its response to flotation. Miner. Eng. 137, 1-9. doi: 10.1016/j.mineng.2019.03.021

Feng, Q., Zhao, W., and Wen, S. (2017). Surface modification of malachite with ethanediamine and its effect on sulfidization flotation. Appl. Surf. Sci. 436, 823-831. doi: 10.1016/j.apsusc.2017.12.113

Hirajima, T., Miki, H., Suyantara, G. P. W., Matsuoka, H., Elmahdy, A. M., Sasaki, K., et al. (2017). Selective flotation of chalcopyrite and molybdenite with $\mathrm{H}_{2} \mathrm{O}_{2}$ oxidation. Miner. Eng. 100, 83-92. doi: 10.1016/j.mineng.2016. 10.007

Hosseini, S. H., and Forssberg, E. (2006). Adsorption studies of smithsonite flotation using dodecylamine and oleic acid. Mining Metall. Expl. 23, 87-96. doi: 10.1007/BF03403341

Hosseini, S. H., and Forssberg, E. (2007). Physicochemical studies of smithsonite flotation using mixed anionic/cationic collector. Miner. Eng. 20, 621-624. doi: 10.1016/j.mineng.2006.12.001

Irannajad, M., Nuri, O. S., and Mehdilo, A. (2019). Surface dissolutionassisted mineral flotation: a review. J. Environ. Chem. Eng. 7:103050. doi: 10.1016/j.jece.2019.103050

Kai, J., Feng, Q., Zhang, G., Ji, W., Zhang, W., and Yang, B. (2018). The role of $\mathrm{S}(\mathrm{II})$ and $\mathrm{Pb}(\mathrm{II})$ in xanthate flotation of smithsonite: surface properties and mechanism. Appl. Surf. Sci. 442, 92-100. doi: 10.1016/j.apsusc.2018. 02.132 
Kashani, N. A. H., and Rashchi, F. (2008). Separation of oxidized zinc minerals from tailings: influence of flotation reagents. Miner. Eng. 21, 967-972. doi: 10.1016/j.mineng.2008.04.014

Khmeleva, T. N., Georgiev, T. V., Jasieniak, M., Skinner, W. M., and Beattie, D. A. (2010). XPS and ToF-SIMS study of a chalcopyrite-pyrite-sphalerite mixture treated with xanthate and sodium bisulphite. Surf. Interface Anal. 37, 699-709. doi: 10.1002/sia.2067

Khmeleva, T. N., Skinner, W., and Beattie, D. A. (2005). Depressing mechanisms of sodium bisulphite in the collectorless flotation of copper-activated sphalerite. Int. J. Miner. Process. 76, 43-53. doi: 10.1016/j.minpro.2004.10.001

Kiersznicki, T., Majewski, J., and Mzyk, J. (1981). 5-alkylsalicylaldoximes as collectors in flotation of sphalerite, smithsonite and dolomite in a Hallimond tube. Int. J. Miner. Process. 7, 311-318. doi: 10.1016/0301-7516(81)90026-0

Liu, C., Ai, G., and Song, S. (2018a). The effect of amino trimethylene phosphonic acid on the flotation separation of pentlandite from lizardite. Powder Technol. 336, 527-532. doi: 10.1016/j.powtec.2018.06.030

Liu, C., Chen, Y., Song, S., and Li, H. (2018b). The effect of aluminum ions on the flotation separation of pentlandite from lizardite. Colloids Surf. A Physicochem. Eng. Asp. 555, 708-712. doi: 10.1016/j.colsurfa.2018.07.054

Liu, J., Ejtemaei, M., Nguyen, A. V., Wen, S., and Zeng, Y. (2020). Surface chemistry of Pb-activated sphalerite. Miner. Eng. 145:106058. doi: 10.1016/j.mineng.2019.106058

Liu, J., Wang, Y., Luo, D., and Zeng, Y. (2018). Use of $\mathrm{ZnSO}_{4}$ and SDD mixture as sphalerite depressant in copper flotation. Miner. Eng. 121, 31-38. doi: 10.1016/j.mineng.2018.03.003

Liu, J., Wen, S., Deng, J., Chen, X., and Feng, Q. (2014). DFT study of ethyl xanthate interaction with sphalerite $\left(\begin{array}{lll}1 & 1 & 0\end{array}\right)$ surface in the absence and presence of copper. Appl. Surf. Sci. 311, 258-263. doi: 10.1016/j.apsusc.2014.05.052

Popov, S. R., and Vučini, D. R. (1990). The ethylxanthate adsorption on copper-activated sphalerite under flotation-related conditions in alkaline media. Int. J. Miner. Process. 30, 229-244. doi: 10.1016/0301-7516(90)9 0017-S
Rao, S. R., and Finch, J. A. (2003). Base metal oxide flotation using long chain xanthates. Int. J. Miner. Process. 69, 251-258. doi: 10.1016/S0301-7516(02)00130-8

Smart, R. S. C., Skinner, W. M., and Gerson, A. R. (2015). XPS of sulphide mineral surfaces: metal-deficient, polysulphides, defects and elemental sulphur. Surf. Interface Anal. 28, 101-105. doi: 10.1002/(SICI)10969918(199908)28:1<101::AID-SIA627>3.0.CO;2-0

Suyantara, G. P. W., Hirajima, T., Miki, H., Sasaki, K., Yamane, M., Takida, E., et al. (2018). Selective flotation of chalcopyrite and molybdenite using $\mathrm{H}_{2} \mathrm{O}_{2}$ oxidation method with the addition of ferrous sulfate. Miner. Eng. 122, 312-326. doi: 10.1016/j.mineng.2018.02.005

Wu, D., Ma, W., Wen, S., Bai, S., Deng, J., and Yin, Q. (2017). Contribution of ammonium ions to sulfidation-flotation of smithsonite. J. Taiwan Inst. Chem. Eng. 78, 20-26. doi: 10.1016/j.jtice.2017.05.015

Wu, D., Wen, S., Deng, J., Liu, J., and Mao, Y. (2015). Study on the sulfidation behavior of smithsonite. Appl. Surf. Sci. 329, 315-320. doi: 10.1016/j.apsusc.2014.12.167

Xing, Y., Gui, X., and Cao, Y. (2017). The hydrophobic force for bubbleparticle attachment in flotation-a brief review. Phys. Chem. Chem. Phys. 19, 24421-24435. doi: 10.1039/C7CP03856A

Conflict of Interest: The authors declare that the research was conducted in the absence of any commercial or financial relationships that could be construed as a potential conflict of interest.

Copyright (c) 2020 Zeng, Liu, Dong, Hao and Wang. This is an open-access article distributed under the terms of the Creative Commons Attribution License (CC BY). The use, distribution or reproduction in other forums is permitted, provided the original author(s) and the copyright owner(s) are credited and that the original publication in this journal is cited, in accordance with accepted academic practice. No use, distribution or reproduction is permitted which does not comply with these terms. 